\title{
Transgenic potato plants can be used to evaluate stability of foreign genes: reversions and chimeras in multiple copies of rolC harboring clones
}

\author{
M Fladung * \\ Abteilung Pflanzenzüchtung und Entragsphysiologie, Max-Planck-Institut für Züchtungsforschung, D-50829 Cologne, Germany
}

(Received 3 August 1995; accepted 28 December 1995)

\begin{abstract}
Summary - 35S-rolC and rbcS-rolC transgenic potato plants were used to evaluate the stability of the phenotypic marker gene rolC during the life cycle of transgenic potato plants and in subsequent vegetative generations. Transgenics carrying one or two copies of the gene revealed a high stability of the gene during growth and vegetative propagation. Two $35 S-r o l C$ transgenic plants harboring four and five copies of the rol $C$ gene showed a strong phenotypic rolC expression and were viable only when grown in vitro. Under these conditions, spontaneous reversions were observed to a less expressed rolC phenotype. In Southern experiments, these transgenics still carried four and five copies of the rolC gene, whereas the northern blot signals were comparable to those of transgenics carrying a lower copy number of rolC. From the same two clones, chimeric shoots were observed during vegetative growth in a greenhouse that showed light and dark green normal sectors on the same leaf. The presence of four or five copies of ro/C was confirmed in the dark green normal sectors, although no signal was obtained in northern blots for this phenotypically normal tissue. The results are discussed with respect to possible gene inactivation.
\end{abstract}

chimera / marker gene / ro/C / stability / transgenic potato

Résumé - Des plantes de pomme de terre transgéniques peuvent être utilisées pour évaluer la stabilité de gènes exotiques : réversions et chimères dans des clones hébergeant des copies multiples. Des plantes de pomme de terre 35S-rolC et rbcS-rolC ont été utilisées pour évaluer la stabilité du gène marqueur phénotypique rolC pendant le cycle de végétation de plantes de pomme de terre transgéniques et pendant les générations végétatives subséquentes. Les transgéniques qui portent une ou deux copies du gène manifestent une stabilité élevée du gène pendant leur croissance et leur propagation végétative. Deux plantes 35S-rolC hébergeant quatre et cinq copies du gène rolC ont manifesté une forte expression phénotypique et étaient viables cultivées in vitro. Dans ces conditions, des réversions spontanées vers un phénotype moins fortement exprimé ont été observées. Dans des Southern ces transgéniques se sont avérées toujours porter quatre ou cinq copies du gène rolC, alors que leurs signaux en northern étaient comparables à ceux de transgéniques portant un nombre inférieur de copies de rolC. $\dot{A}$ partir des mêmes deux clones, des tiges chimériques ont été observées, pendant la croissance végétative en serre, présentant des secteurs vert foncé et normaux, sur la même feuille. La présence de quatre ou cinq copies de rolC a été confirmée dans les secteurs vert foncé, bien qu'on n'obtienne pas de signal en northern pour ce tissu phénotypiquement normal. Les résultats sont discutés dans la perspective d'une possible inactivation du gène.

chimère / gène marqueur / rolc / stabilité / pomme de terre transgénique

\footnotetext{
* Present address: Bundesforschungsanstalt für Forst- und Holzwirtschaft, Institut für Forstgenetik, Sieker Landstr 2, 22927
} Grosshansdorf, Germany 


\section{INTRODUCTION}

The stable expression of foreign genes is an essential requirement for the use of transgenic plants in plant breeding. This includes gene stability in somatic tissues of the plant during the life cycle, as well as in subsequent generations. In addition, for the establishment of multiple copy versions of foreign genes in transgenic plants in order to enhance gene expression, it is important to know whether spontaneous inactivation of some copies of the transferred genes can take place during sexual or vegetative propagation.

To evaluate these and related problems, a screenable morphological marker has some advantages compared to biochemical markers. First, morphological markers can be detected phenotypically during every stage of the life cycle or at least at specific developmental stages (eg, flower color) of the plant, whereas marker genes such as npt-I/ or uidA only give results at the time of evaluation and not between determinations. Second, the gene product of the marker gene should be cell-specific and not diffusable to adjacent cells and therefore detectable at the cell level. Plants transgenic for the rolC of Agrobacterium rhizogenes offer an appropriate system combining both requirements mentioned. Tobacco and potato plants transgenic for the rolC gene under the control of the strong and constitutive 35S-promoter of the cauliflower mosaic virus reveal remarkably modified leaf and flower size, leaf color and pollen fertility, together with reduced apical dominance (Fladung, 1990; Fladung and Ballvora, 1992; Schmülling et al, 1988; Spena et al, 1987). When transgenics were produced carrying the sarne rolC gene but under the control of the light-inducible rbcS promoter (Fladung et al, 1993), transgenic potato plants were only slightly reduced in size with no remarkable reduction in apical dominance, but still with light green leaves when compared to the darker green ones of control plants. All these morphological alterations can be used as markers for gene expression, somatic hybridization (Kaendler, 1993), sexual inheritance ratios or transposon excision (Spena et al, 1989).

When foreign genes are newly introduced in plants, changes in gene expression have been reported. This has been ascribed to the mode of transformation, regeneration and growth environment of transgenic plants (Meyer et al, 1992) or to the number of T-DNA's present in the plant
(Hobbs et al, 1990; Linn et al, 1990; Matzke et al, 1989). Gene inactivation has been mainly reported as due to methylation or genomic rearrangements (Hobbs et al, 1990; Matzke et al, 1989; Visser et al, 1989; Wirtz et al, 1987), which would result in an absence of the primary transcript due to no, or poorly transcribed, methylated loci (Bird, 1992; Meyer et al, 1993; Neuhuber et al, 1994). However, gene silencing is not always found at the transcriptional level, but can also occur at a post-transcriptional level (De Carvalho et al, 1992). In particular for co-suppression phenome$\mathrm{na}$, the presence of a transcript has been shown in nuclear run-on experiments indicating a posttranscriptional mechanism, because the transcript was synthezised in the nucleus, but did not accumulate in the cytosol (van Blockland et al, 1994)

In this paper, data are summarized concerning a phenotypically marked gene in experiments involving its stability during growth and vegetative propagation of transgenic potato plants. All transgenics used were primary transformants carrying one or more copies of the TDNA (Fladung and Ballvora, 1992; Fladung et al, 1993), and therefore were heterozygous for the rolC gene.

\section{MATERIAL AND METHODS}

\section{Plant material, transformation of potato, DNA and RNA analysis}

The tetraploid potato clone $\mathrm{Z} 2$ was transformed with the plasmid pPCV002-CaMVC (Spena et al, 1987), which carries the rolC gene from Agrobacterium rhizogenes under the control of the cauliflower mosaic virus $35 S$ RNA promoter and a selectable kanamycin resistance gene. This was the origin of the 35S-rolC transgenic clones (Fladung, 1990; Fladung and Ballvora, 1992). An analogous construct, in which the $35 S$ promoter was replaced by the light-inducible promoter of the small subunit of the ribulose-bisphosphate carboxylase gene of potato ( $r b c S 1$, Fritz, 1988), was used to transform the same potato clone $Z 2$ to obtain independent rbcS-rolC transgenics (Fladung et al, 1993). The binary vector pPVC002 (without the rolC gene; Koncz and Schell, 1986) was employed for transformation, yielding the transformed control clone (TC). As the untransformed control (UTC), regenerated Z2 plants derived from tissue culture were used. Copy number and level of ro/C expression were established by Southern blot and northern blot experiments respectively, as described elsewhere (Fladung and Ballvora, 1992) 


\section{Plant cultivation and morphological evaluations}

Plants propagated in vitro were transferred and grown to maturity in a standard $\mathrm{S} 1$ greenhouse or in a growth chamber (BBC York International) under constant temperatures of $20{ }^{\circ} \mathrm{C}$ during the day and $16{ }^{\circ} \mathrm{C}$ during the night, and $80 \%$ relative humidity.

For evaluation of phenotype the transformed plantlets were compared to untransformed and transformed control plants grown simultaneously. Potato plants transgenic for the 35S-rolC construct were bushy with reduced apical dominance and shortened internodes (Fladung, 1990), while rbcS-rolC transgenics were only slightly reduced in plant size (Fladung et al, 1993). Another easily detectable trait was the lowered chlorophyll content in leaves of both 35S-ro/C and rbcS-rolC transgenic clones (Fladung, 1990; Fladung and Gieffers, 1993; Fladung et al, 1993). Phenotypically, this trait was visible as light green leaves compared to the darker green ones of the controls.

\section{RESULTS}

\section{Vegetative propagation}

After transformation and regeneration of transformed plantlets, in total more than 10000 shoots were propagated in vitro and more than 800 were transferred to the greenhouse. All transgenics carrying one or two copies of rolC revealed their typical rolC specific traits in all shoots produced during their life cycle. Out of these, tubers of the first, second and third generations from various transformants of independent origin were planted and analyzed with respect to the expression of ro/C-related traits during the years 1988 and 1992 (table I). In every stage of vegetative propagation, no reversion to wildtype was observed. Furthermore, among 15000 plants of a clone harboring only one copy of the rolC gene grown from isolated eye sections of tubers of the second generation, in all plants a fully developed rolC phenotype was recognized by visual inspection (Ballvora and Fladung, unpublished). The same result was observed after in vitro germination of in total 877 tubers obtained by in vitro tuber induction.

\section{Revertants and chimeras}

Independent ro/C transformants show different levels of expression of the traits induced by the presence of the rolC gene. In extreme cases potato plants showed a moss-like phenotype (fig 1A). These plants were viable only in vitro. Determination of copy number was carried out after digestion of genomic DNA with restriction enzymes (either EcoRI or Hind III), which cut at the restriction sites of the cassette in the vector pPCV002 flanking the construction at the $5^{\prime}$ and $3^{\prime}$ ends respectively. Southern blot experiments showed that they contained four and five copies of the rolC gene integrated in the genome (clones T344,I and T354,I respectively, in fig 2). Double digest with EcoRI and HindIII revealed the isolated insert of about $1.6 \mathrm{~kb}$. During continuous in vitro culture of these clones, shoots with a different expression of ro/C-related traits spontaneously appeared among the shoots of the moss-like transgenics. For both $\mathrm{T} 344, \mathrm{I}$ and T354,I, two phenotypically different types of shoots were isolated and transferred to the greenhouse (fig 1B): types II and III, phenotypically resembling rolC transgenic clones harboring only two copies or one copy, respectively, of the rolC gene. Southern analysis still revealed the presence of four or five copies of the rolC gene in the genome of these revertants (T344,III or T354,II in fig 2). T342 was the kanamycin resistant control carrying the cas-

Table I. Number of independent transformants and plants analyzed for the expression of the ro/C gene in transgenic potato in the first, second and third tuber generations.

Tuber generation

1 st

2nd

3rd
No of independent transformants

$10^{a}$

$10^{\mathrm{a}}$

$6^{b}$
No of plants analyzed

1443
2014
2325


sette of the binary vector without the rolC gene. When analyzed by northern experiments, the strongest signal was obtained from the original transformant (T344,I in fig 2), identified as the mRNA product of rolC (approximately $0.54 \mathrm{~kb}$ ). The revertants T344, II and T344,II revealed bands which were of comparable intensity to those of 35S-rolC transgenic clones carrying one (T351) or two (T333) copies of the gene construct (fig 3A). Again, T342 served as the rolC negative control.

During the growth of revertants of type III of both clones in the greenhouse, shoots were observed showing chimeric leaves in these plants. These shoots were cut and rooted suc- cessfully. The chimeric composition was seen as light green leaf tissue of transgenic origin and dark green wildtype sectors in the same leaf (fig $1 C, D)$. In Southern analysis, even the dark green tissues revealed five copies of the rolC gene in the genome (type T354,D in fig 2). The same result was found for dark green sectors of the T344 chimeric plant. In northern experiments, a rolC transcript was detected in light green sectors of leaves only $(\mathrm{T} 344 \mathrm{H}, \mathrm{T} 354 \mathrm{H})$, which was of similar size and abundance to that in a 35S-rolC transgenic (T341) harboring one copy of the gene. No transcript was found in the dark green sectors (T344,D, T354,D) or in leaves of the control transformant T342 (fig 3B).
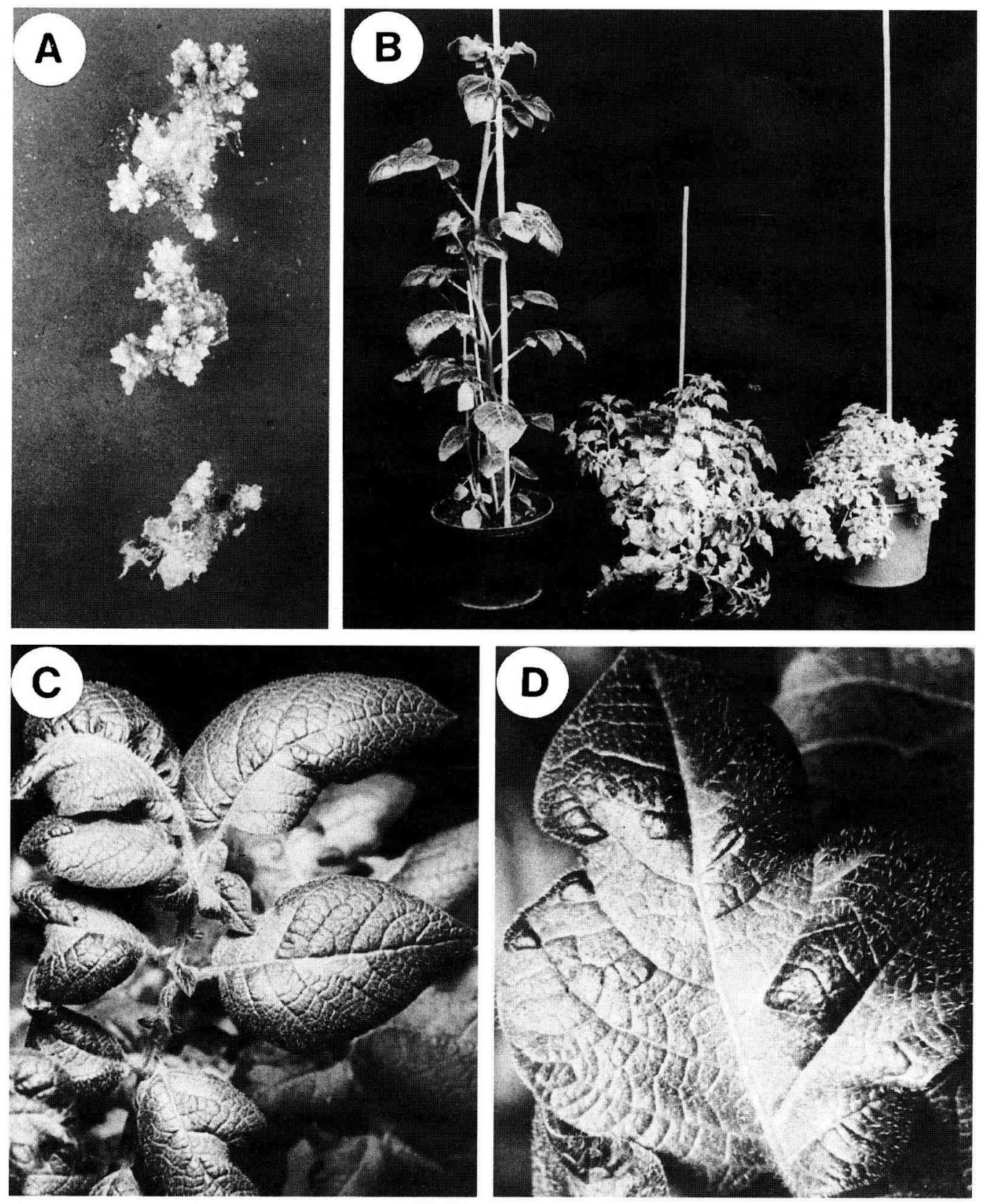

Fig 1. Phenotype of transgenics harboring multiple copies of rolC, revertants and chimeras in potato: $A$, moss-like transgenis T354; $\mathrm{B}$, two revertants (middle [III] and right [II]) of T354, I, showing different phenotypic expression of rolC; left, untransformed control of the same age; $C$ and $D$, leaves of the chimeric T354, III plant. 


\section{T342 T344,I T344,III T354,I T354,II T354,D}

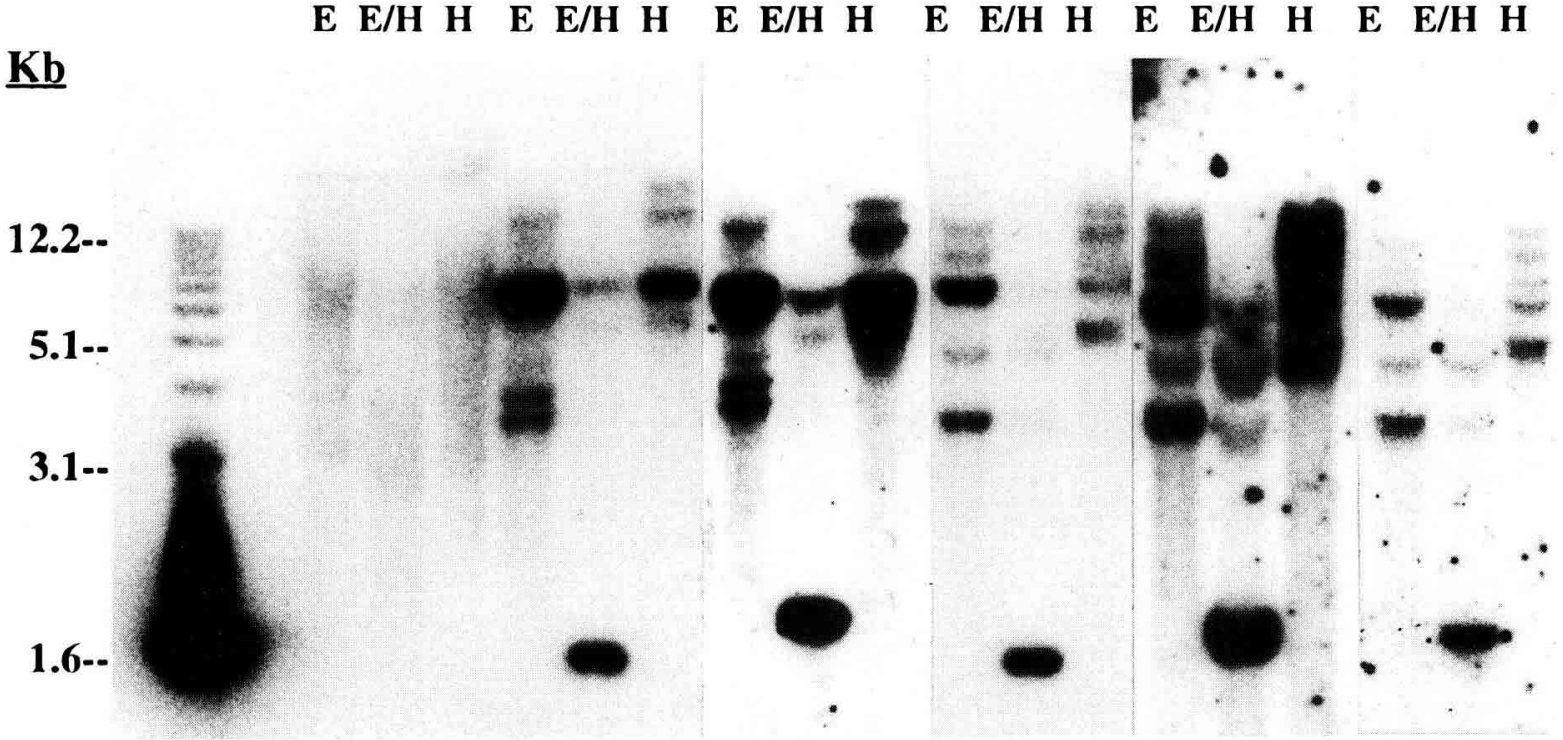

Fig 2. Southern blot analysis of DNA extracted from potato leaves transgenic for the rolC gene. Ten milligrams of restriction enzyme digested DNA $(E=E c O R I, H=$ HindIII, $E / H=E c o R I$ and HindlII) was loaded in each slot, blotted and probed against $0.1 \mu \mathrm{rg}$ rolC insert. The double digest with EcoRI and HindIII restriction flanking the cassette showed the isolated insert of $1.6 \mathrm{~kb}$ in every case. $\mathrm{T} 342$ is the kanamycin resistant control plant without the rolC gene. T344,III and T354,II indicate revertants of T344,I or T354,I. T354,D identifies the green sectors of the chimeric plant.

\section{DISCUSSION}

Stability of foreign genes in transgenic plants during vegetative growth and sexual propagation is important when introducing transgenic plants in plant breeding. Inheritance and expression of, eg, kanamycin resistance were shown to be Mendelian in a number of species like tobacco, petunia and potato (Budar et al, 1986; De Block et al, 1984; Deroles and Gardner, 1988a,b; Peerbolte et al, 1987). After visual inspection of transgenic seedlings, a Mendelian inheritance was also found in selfings or crosses of 35S-rolC and $r b c S$-rolC transgenic tetraploid potato plants with controls or other transgenic clones (data not shown).

The advantage of using phenotypically visible marker genes is that genetic changes can be easily followed visually at every, or at least one, specific developmental stage during growth of the plant. Therefore, rolC transgenic plants have been chosen as an appropriate model to study somatic stability of genes in growing tissues or after vegetative reproduction. Another advantage of rolC transgenic plants, besides the phenotypically visible consequence of transformation, is that the expression of the rolC syndrome in transformants show a positive correlation to the expression level of the rolC gene, which is based on the number of copies involved (Fladung,
1990; Fladung and Ballvora, 1992). Furthermore, possible position effects on the rate of expression of the rolC gene are phenotypically detectable (Fladung and Ballvora, 1992).

For the potato, studies of the presence and vegetative transmission of introduced genes are so far sparse. In tubers of vegetatively propagated potato clones, no variation in the expression of the introduced genes was observed after various tuber propagations (Ottavani et al, 1990). This finding was confirmed in $35 S-r o l C$ and $r b c S-$ rolC transgenic potato clones. Neither during in vitro propagation of in total more than 10000 shoots of clones harboring one or two copies of rolC, nor during five years of cultivation in the greenhouse, was any reversion to wildtype observed in the first, second or third tuber generations. Additionally in our experiments, when the transgenics were grown under varyious environments (Fladung and Ballvora, 1992) or treated with various levels of different hormones or growth retardants (morphaktins) in vitro as well as in the greenhouse (Fladung, unpublished results), no evidence for reversions was found. However, no data are currently available as to how these transgenics react when they are treated with high temperature, intense light or drought.

An example that something can happen regarding somatic stability of foreign genes in 


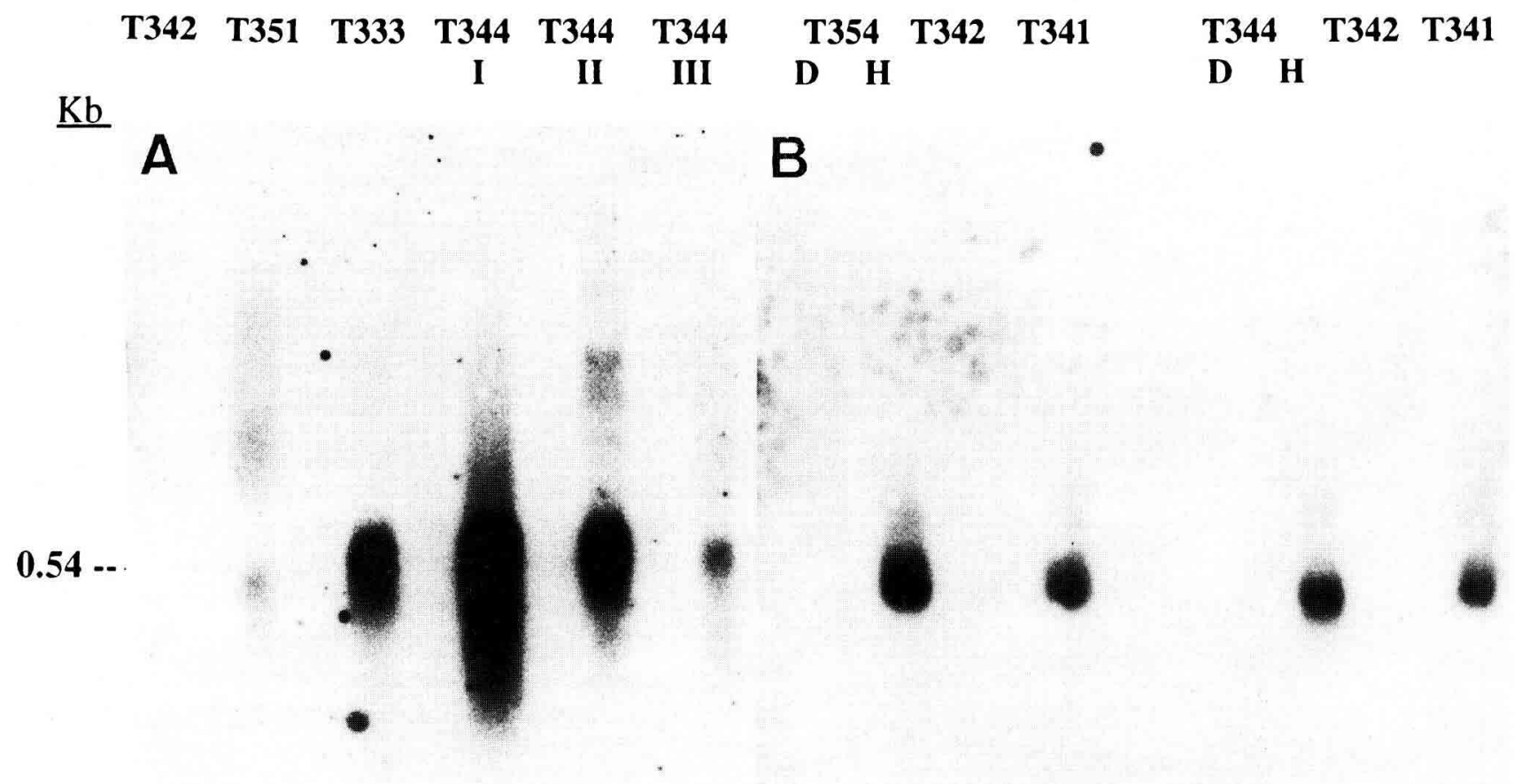

Fig 3. Northern blot analysis of RNA extracted from potato leaves transgenic for the rolC gene. Fifty milligrams of total RNA in each slot was blotted after electrophoresis. No signal was found for the control plant T342. A: increasing levels of rolC expression were detected in T351 (one copy of rolC), T333 (two copies of rolC, Fladung and Ballvora, 1992) and T344,I (four copies of rolC). Decresing levels were found in revertants T344,II and T344,III. B: no signal was detected in green sectors (D) of the chimeras of T344 and T354, whereas a signal was found in the light green sectors $(H)$. This signal was of comparable sensitivity of that found in T341, carrying one copy of rolC (Fladung and Ballvora, 1992).

transgenic plants is shown in both the potato clones harboring four or five copies of $35 \mathrm{~S}-\mathrm{rol} C$, which gave high rolC expression resulting in a strong rolC phenotype in transgenic clones. These clones were only viable in vitro and were therefore kept alive by subsequent subcultivations on agar plates. Sometimes, in these in vitro grown clones, reversions were observed leading to plants with a weaker phenotype due to lower rolc expression. These plants could be isolated and transferred to the greenhouse, and their rolC copy number was shown to be the same as for the in vitro plantlets. It is suggested that the four or five copies of rolC within the genome interact and lead to the inactivation of three or more copies, or partial inactivation of some or all copies. Possible reasons for inactivations at the gene level are somatic instability caused by insertion of movable genetic elements (Spena et al, 1989) or deletion of the whole or parts of the gene. However, this would be detectable on Southern blots by a remarkable change of the band sizes and there was no indication of this (fig 2). Mutations of the gene or unequal crossingover are further possible reasons for inactivation of a gene, but it is very unlikely that one of these mechanisms would affect more than one copy of the transgene.
At the expression level, gene silencing has first been reported in transgenic plants, where one gene of the transferred DNA influenced another gene of an unlinked transferred DNA (Matzke et al, 1989). The result was an inactivation of the original gene locus in some transformants. A negative influence of the gene copy number on the expression of the transferred gene was suggested at the transcriptional level (Hobbs et al, 1990, 1993; Linn et al, 1990; Matzke et al, 1989). This homology-dependent gene trans-inactivation was assumed when multiple copies were closely linked as well as when these were located on separate DNA molecules (Matzke and Matzke, 1993; Matzke et al, 1994). In many cases, the inactivation of transgenes is associated with methylation of either promoter or gene sequences, or both (Hobbs et al, 1990, 1993; Linn et al, 1990; Matzke et al, 1989; Meyer et al, 1993; Vaucheret, 1993). Methylated loci are not, or are poorly, transcribed (Bird, 1992; Meyer et al, 1993; Neuhuber et al, 1994). However, the level of trans-inactivation varies among and even within transgenics. The reasons for this variability and the sometimes low frequencies of gene inactivation are not understood so far. It seems likely that the characteristics of the transformants themselves, as copy number, integration sites, 
expression level or structure of the integrated TDNA, could be important features (De Lange et al, 1995).

Gene inactivation was, however, found very often to involve no modification of gene expression at the transcriptional level (Hart et al, 1992). In nuclear run-on experiments, it was shown that nascent RNA transcription is unaffected but no transcript was present in the cytosol (Van Blokland et al, 1994). Possible mechanisms (for a review, see Flavell et al, 1995) involved in the degradation of specific mRNAs are due to antisense RNA (Grierson et al, 1991; Mol et al, 1994), inhibition of RNA transport or RNA stability levels (De Carvalho Niebel et al, 1995). Posttranscriptional silencing has been shown in particular for co-suppression phenomena, where the transgene and homologous host genes were coordinately suppressed in plants (Napoli et al, 1990).

In this study, revertant sprouts of different expression of the rolC syndrome spontaneously appeared during in vitro culture of the potato lines T344,I and T354,I harboring multiple copies of $35 \mathrm{~S}-\mathrm{rol} \mathrm{C}$. This indicates an inactivation of one or more copies of the rolC gene simultaneously. Therefore, the 'inactivation-stimulus' observed in these multiple copies of 35S-rolC-harboring clones acts spontaneously at the regeneration level, and results in different revertants revealing different rolC phenotypes. Tissue culture has already been proposed to function as an environmental stimulus of transgene inactivation in a multiple copy harboring petunia line due to hypermethylation (Renckens et al, 1992). The different rolC phenotypes observed could be correlated with rolC signal intensity observed in northern blot experiments, indicating that the rolC genes were transcribed at different levels. Differences in signal intensity may be due to different epigenetic states of some or all rolC copies (Meyer and Heidmann, 1994). No signal indicated the complete inactivation of all copies of rolC (see D-sectors in fig $3 \mathrm{~B}$ ), and the strongest signal possibly indicated the fully activated state (T344, in fig $3 A)$. Intermediate signals may be due to complete inactivation of some copies of the transgene or to partial inactivation of some or all copies. Therefore, it might be suggested that either some active copies of the transgene can occur simultaneously with inactivated ones, or the state of partial inactivation of the copies involved varies among reverted plants.

A similar explanation is not possible per se for the chimeric plants described in this paper. In these plants, the chimeric status was obtained by spontaneous chimerism of side shoots of rolC plants (revertants of type III) grown in the greenhouse. This clearly rules out a tissue culture effect causing inactivation of the rolC gene. The rolC transcripts of the light green sectors of the chimeric plants detected in northern experiments (fig 3B) were of similar size and abundance to that of a transgenic line harboring one copy of rolC. This indicates that possibly inactivated copies of rolC were already present in the genome of these type III revertants. How far these copies have influenced homologous active copies of the transgene leading to the chimeric state cannot be decided at this stage of experiments. The chimeras found in this study, which were obtained by spontaneous chimerism of side-shoots of non-chimeric revertant plants, were possibly sectorial (Poethig, 1987). In such chimeras the clonal progeny of a mutated cell occupies all three layers (L1, L2, L3) of a sector of the apical meristem (Poethig, 1987). These plants differ clearly from the periclinal chimeras found in 35S-rolC transgenic tobacco plants (Schmülling and Schell, 1993), in which the layer L2 was found to be wildtype and L3 rolC-positive, and also from mericlinal chimeras (Rives, 1970). The light green and dark green sectors detected phenotypically, because all four or five copies of rolC were inactivated, were therefore suggested to be homogeneous within the leaves Instabilities of other genes with no phenotypic consequences cannot be revealed by visual analysis. Therefore, transgenic plants produced so far could be sectorial genetic chimeras, which could not be identified as such because of the absence of a morphological selectable marker.

\section{ACKNOWLEDGMENT}

I am very grateful to F Salamini (Max-Planck-Institut für Züchtungsforschung, Cologne, Germany) for enabling me to carry out the work in his department, and anonymous referees for critically reviewing this manuscript.

\section{REFERENCES}

Bird A (1992) The essentials of DNA methylation. Cell 70, 5-8

Budar F, Thia-Toong L, Van Montagu M, Hernalsteens JP (1986) Agrobacterium mediated gene transfer results mainly in transgenic plants transmitting T-DNA as a single Mendelian factor. Genetics 114, 303-313

De Block M, Herrera-Estrella L, Van Montagu M, Schell J, Zambryski P (1984) Expression of foreign 
genes in regenerated plants and in their progeny. EMBO J 3, 1681-1689

De Carvalho F, Gheysen G, Kushnir S, Van Montagu M, Inzé D, Caestresana C (1992) Suppression of beta-1,3-glucanase transgene expression in homozygous plants. EMBO J11, 2595-2602

De Carvalho Niebel F, Frendo $P$, Inzé D, Cornelissen $M$, Van Montagu M (1995) Co-suppression of $\beta-1,2-$ glucanase genes in Nicotiana tabacum. In: Current Topics in Microbiology and Immunology: Gene Silencing in Higher Plants and Related Phenomena in Other Eukaryotes (P Meyer, ed), Springer Verlag Berlin, 91-103

De Lange $P$, Van Blockland R, Kooter JM, Mol JNM (1995) Suppression of genes in higher plants by the introduction of antisense and sense genes. In: Current Topics in Microbiology and Immunology: Gene Silencing in Higher Plants and Related Phenomena in Other Eukaryotes (P Meyer, ed), Springer Verlag Berlin, 57-75

Deroles SC, Gardner RC (1988a) Expression and inheritance of kanamycin resistance in a large number of transgenic petunias generated by Agrobacterium-mediated transformation. Plant Mol Biol 11, 355-364

Deroles SC, Gardner RC (1988b) Analysis of the TDNA structure in a large number of transgenic petunias generated by Agrobacterium-mediated transformation. Plant Mol Biol 11, 365-377

Fladung M (1990) Transformation of diploid and tetraploid potato clones with the rolC gene of Agrobacterium rhizogenes and characterization of transgenic plants. Plant Breeding 104, 295-304

Fladung M, Ballvora A (1992) Further characterization of rolC transgenic tetraploid potato clones, and influence of daylength and level of rolC expression on yield parameters. Plant Breeding 109, 18-27

Fladung M, Gieffers W (1993) Resistance reactions of leaves and tubers of rolC transgenic tetraploid potato to bacterial and fungal pathogens. Correlation with sugar, starch and chlorophyll content. Physiol Mol Plant Pathol 42, 123-132

Fladung M, Ballvora A, Schmülling T (1993) Constitutive or light regulated expression of the rolC gene in transgenic potato plants has different effects on yield attributes and tuber carbohydrate composition. Plant Mol Biol 23, 749-757

Flavell RB, O'Dell M, Metzlaff S, Bonhomme S, Cluster PD (1995) Developmental regulation of co-suppression in Petunia hybrida. In: Current Topics in Microbiology and Immunology: Gene Silencing in Higher Plants and Related Phenomena in Other Eukaryotes (P Meyer, ed), Springer Verlag Berlin, 43-56

Fritz C (1988) Molekulare Analyse der Struktur und Expression einer pflanzlichen Genfamilie. Die tbcS Gene in Solanum tuberosum. PhD Thesis, University of Cologne

Grierson D, Fray RG, Hamilton AJ, Smith CJS, Watson CF (1991) Does cosuppression of sense genes in transgenic plants involve antisense RNA? Trends Biotechnol 9, 122-123

Hart CM, Fischer B, Neuhaus JM, Meins F (1992) Regulated inactivation of homologous gene expression in transgenic Nicotiana sylvestris plants containing a defense-related tobacco chitinase gene. Mol Gen Genet 235, 179-188

Hobbs SLA, Kpodar P, DeLong CMO (1990) The effect of T-DNA copy number, position and methylation on reporter gene expression in tobacco transformants. Plant Mol Biol 15, 851-864

Hobbs SLA, Warkentin TD, DeLong CMO (1993) Transgene copy number can be positively or negatively associated with transgene expression. Plant Mol Biol 21, 17-26

Kaendler C (1993) Somatische Hybriden zwischen Solanum tuberosum $L$ subsp tuberosum $(2 X)$ und Solanum papita Rydb (2X). PhD Thesis, University of Cologne

Koncz C, Schell J (1986) The promoter of the TL-DNA gene 5 controls the tissue-specific expression of chimaeric genes carried by a novel type of Agrobacterium vector. Mol Gen Genet 204, 383-396

Linn F, Heidmann I, Saedler H, Meyer P (1990) Epigenetic changes in the expression of the maize A1 gene in Petunia hybrida: role of numbers of integrated gene copies and state of methylation. $\mathrm{Mol}$ Gen Genet 222, 329-336

Matzke MA, Matzke AJM (1993) Genomic imprinting in plants - parental effects and trans-inactivation phenomena. Ann Rev Plant Physiol 44, 53-76

Matzke MA, Primng M, Trnovshy J, Matzke AJM (1989) Reversible methylation and inactivation of marker genes in sequentially transformed tobacco plants. EMBO J 8, 643-649

Matzke AJM, Neuhuber F, Park YD, Ambros PF, Matzke MA (1994) Homology-dependent gene silencing in transgenic plants: epistatic silencing loci contain multiple copies of methylated transgenes. Mol Gen Genet 244, 219-229

Meyer P, Heidmann I (1994) Epigenetic variants of a transgenic petunia line show hypermethylation in transgene DNA: an indication for specific recognition of foreign DNA in transgenic plants. Mol Gen Genet 243, 390-399

Meyer P, Linn F, Heidmann I, Meyer zA H, Niedenhof I, Saedler H (1992) Endogenous and environmental factors influence $35 \mathrm{~S}$ promoter methylation of a maize A1 gene construct in transgenic petunia and its colour phenotype. Mol Gen Genet 231, 345-352

Meyer P, Heidmann I, Niedenhof I (1993) Differences in DNA-methylation are associated with a paramutation phenomenon in transgenic petunia. Plant $J$ 13, 2084-2088

Mol JNM, Van Blokland R, De Lange P, Stam M, Kooter JM (1994) Post-transcriptional inhibition of gene expression: sense and antisense genes. In: Gene Inactivation and Homologous Recombination in plants (J Paszkowski, ed), Kluwer Academic, Dordrecht, 309-334 
Napoli C, Lemieux C, Jorgensen R (1990) Introduction of a chimeric chalcone synthase gene into petunia results in reversible co-suppression of homologous genes in trans. Plant Cell 2, 279-289

Neuhuber F, Park Y, Matzke AJM, Matzke MA (1994) Susceptibility of transgene loci to homology-dependent gene silencing. Mol Gen Genet 244, 230-241

Ottavani MP, Schel JHN, Hänisch ten Cate CH (1990) Variation in structure and plant regeneration of Agrobacterium rhizogenes transformed and control roots of the potato cv Bintje. Plant Cell Tiss Organ Cult 20, 25-34

Peerbolte R, Floor M, Ruigrok P, Hoge JHC, Wullems GJ, Schilperpoort RA (1987) Stability and expression of transferred DNA in F1 tobacco transformants studied at various states of differentiation. Planta 172, 448-462

Poethig RS (1987) Clonal analysis of cell lineage patterns in plant development. Am J Bot 74, 581-594

Renckens $S$, De Greve $H$, Van Montagu $M$, Hernalsteens JP (1992) Petunia plants escape from negative selection against a transgene by silencing the foreign DNA via methylation. Mol Gen Genet 233, 53-64

Rives M (1970) Chimeras and the like. In: Virus Diseases of Small Fruits and Grapevines ( $A$ Handbook) (WMB Hewitt et al, eds), U Calif Davis, 255-256

Schmülling T, Schell J, Spena A (1988) Single genes from Agrobacterium rhizogenes influence plant development. EMBO J 9, 2621-2639
Schmülling T, Schell J (1993) Transgenic tobacco plants regenerated from leaf disks can be periclinal chimeras. Plant Mol Biol 21, 705-708

Spena A, Schmülling T, Koncz C, Schell J (1987) Independent and synergistic activity of rol $A, B$ and $C$ loci in stimulating abnormal growth in plants. EMBO J 6, 3891-3899

Spena A, Aalen RB, Schulze SC (1989) Cel autonomous behavior of the rolC gene of Agrobacterium rhizogenes during leaf development: a visual assay for transposon excision in transgenic plants. Plant Cell 1, 1157-1164

Van Blokland R, Van der Geest N, Mol JNM, Kooter JM (1994) Transgene-mediated suppression of chalcone synthase expression in Petunia hybrida results from an increase in RNA turnover. Plant $J 6$, 861-877

Vaucheret H (1993) Identification of a general silencer for $19 \mathrm{~S}$ and $35 \mathrm{~S}$ promoters in a transgenic plant: 90 bp of homology in the promoter sequence are sufficient for inactivation. CR Acad Sci Paris, Life Sci 316, 1471-1483

Visser RGF, Hesseling-Meinders A, Jacobsen E, Nijdam H, Withold B, Feenstra WJ (1989) Expression and inheritance of inserted markers in binary vector carrying Agrobacterium rhizogenestransformed potato (Solanum tuberosum). Theor App/ Genet 78, 705-714

Wirtz U, Schell J, Czernilofsky AP (1987) Recombination of selectable maker DNA in Nicotiana tabacum. DNA 6, 245-253 